CLINICAL STUDY

\title{
Performance of salivary cortisol in the diagnosis of Cushing's syndrome, adrenal incidentaloma, and adrenal insufficiency
}

\author{
Filippo Ceccato $^{1}$, Mattia Barbot ${ }^{1}$, Marialuisa Zilio ${ }^{1}$, Sergio Ferasin ${ }^{1}$, Gianluca Occhi ${ }^{1}$, Andrea Daniele ${ }^{1}$, \\ Sara Mazzocut ${ }^{1}$, Maurizio Iacobone ${ }^{2}$, Corrado Betterle ${ }^{1}$, Franco Mantero ${ }^{1}$ and Carla Scaroni ${ }^{1}$ \\ ${ }^{1}$ Endocrinology Unit, Department of Medicine DIMED and ${ }^{2}$ Minimally Invasive Endocrine Surgery Unit, Department of Surgery, \\ University-Hospital of Padova, Via Ospedale, 105, 35128 Padova, Italy \\ (Correspondence should be addressed to C Scaroni; Email: carla.scaroni@unipd.it)
}

\begin{abstract}
Objective: Salivary cortisol has recently been suggested for studies on the hypothalamic-pituitaryadrenal (HPA) axis. The lack of circadian rhythm is a marker of Cushing's syndrome (CS), and some authors have reported that low salivary cortisol levels may be a marker of adrenal insufficiency. The aim of our study was to define the role of salivary cortisol in specific diagnostic settings of HPA axis disease.

Subjects and methods: We analyzed morning salivary cortisol (MSC) and late-night salivary cortisol (LNSC) levels in 406 subjects: 52 patients with Cushing's disease (CD), 13 with ectopic CS, 17 with adrenal CS, 27 with CD in remission (a mean follow-up of $66 \pm 39$ months), 45 with adrenal incidentaloma, 73 assessed as having CS and then ruled out for endogenous hypercortisolism, 75 with adrenal insufficiency, and 104 healthy subjects.

Results: A LNSC value above $5.24 \mathrm{ng} / \mathrm{ml}$ differentiated CS patients from controls with high sensitivity (96.3\%) and specificity (97.1\%); we found higher LNSC levels in ectopic CS patients than in CD patients. We found no difference in MSC and LNSC levels between patients with CD in remission and healthy subjects. Both MSC and LNSC levels were higher in patients with adrenal incidentaloma than in healthy controls. A MSC value below $2.65 \mathrm{ng} / \mathrm{ml}$ distinguished patients with adrenal insufficiency from controls with high sensitivity (97.1\%) and specificity $(93.3 \%)$.

Conclusions: Salivary cortisol is a useful tool to assess endogenous cortisol excess or adrenal insufficiency and to evaluate stable CD in remission.
\end{abstract}

European Journal of Endocrinology 169 31-36

\section{Introduction}

Salivary cortisol is increasingly being used to assess hyper- or hypocortisolism $(1,2)$. The measurement of late-night salivary cortisol (LNSC) levels in combination with the $1 \mathrm{mg}$ dexamethasone suppression test (DST) and that of urinary free cortisol (UFC) levels have been proposed as the first-line laboratory tests in the diagnosis of Cushing's syndrome (CS) (3). The lack of a circadian rhythm is a peculiar marker of CS (4), so the LNSC test seems to be the best choice to screen for CS because of its noninvasive, stress-free, easy collection in outpatients (1). There is a marked variation between studies in the performance of the LNSC test, reflecting differences in laboratory assays, sample collection, severity of CS, and control groups $(2,5,6,7,8,9,10$, $11,12,13,14)$. It is also important to have reference data not only for healthy volunteers but also for a control group of obese, hypertensive, diabetic, and depressed subjects or other clinical features of CS that are common in the general population $(3,15)$. Patients with adrenal incidentaloma are another interesting control group, where mild hypothalamic-pituitaryadrenal (HPA) axis activation is found in a high percentage $(16,17)$.

Although the diagnosis of primary adrenal insufficiency is simple, that of the secondary form is a challenge, and dynamic tests are needed to confirm clinical suspicions (18). Healthy people show physiologically high levels of salivary cortisol when they wake up, and some authors have reported that low salivary cortisol levels may thus be a marker of adrenal insufficiency $(2,6,19)$. None of these studies have looked for differences between primary and secondary adrenal insufficiency; in the latter, some residual HPA axis activity may be confounding.

The aims of our study were to determine the performance of salivary cortisol in specific diagnostic settings: i) as a first test to rule out CS; ii) in a large number of newly diagnosed CS patients of different 
origin (pituitary, ectopic, and adrenal) and in patients with recurrence or remission of Cushing's disease (CD); iii) in patients with adrenal incidentaloma, and iv) in patients with adrenal insufficiency.

\section{Materials and methods}

\section{Patients}

We analyzed 406 consecutive subjects referred from January 2006 to October 2012:

- These included 82 patients with CS (age 46.6 \pm 16.2 years, BMI $28 \pm 5.8 \mathrm{~kg} / \mathrm{m}^{2}$ ): 52 with $\mathrm{CD}, 13$ with ectopic CS, and 17 with adrenal CS. CS diagnosis was made on the basis of two of three abnormal results: the lack of cortisol suppression below $50 \mathrm{nmol} / \mathrm{l}$ after the $1 \mathrm{mg}$ DST, loss of cortisol circadian rhythm (considered if serum cortisol levels were above $50 \mathrm{nmol} / \mathrm{l}$ in sleeping inpatients with an indwelling venous catheter on the second night after admission or if salivary cortisol levels were higher than our local upper limit of normality of $5.24 \mathrm{ng} / \mathrm{ml}$ ), and elevated UFC levels (a mean of two collections, range 30-193 nmol/l). The diagnosis of CD was made on the basis of normal or elevated serum ACTH levels, at least $80 \%$ cortisol suppression after the $8 \mathrm{mg}$ DST, and response to $\mathrm{CRH}$ stimulation $(\mathrm{ACTH}+50 \%$ and cortisol $+20 \%$ increase above the basal levels). Among patients with CD, 41 were newly diagnosed and 11 presented with recurrence. Ectopic CS was confirmed by bilateral petrosal inferior sinus sampling, indicating a non-pituitary ACTH source. Adrenal CS patients were characterized by low serum morning ACTH levels and radiological evidence of adrenal lesions.

- The 27 patients with CD in remission were aged $44.5 \pm 14.6$ years, with a mean follow-up of $66 \pm 39$ (from 14 to 137) months. We considered CD patients to be in remission 12 months after successful pituitary surgery, with no new clinical signs or symptoms of CS and with persistent normal HPA axis parameters based on the criteria detailed above. None were on glucocorticoid replacement therapy.

- In 45 subjects (age $57 \pm 13$ years, BMI 28 $\pm 6 \mathrm{~kg} / \mathrm{m}^{2}$ ), an adrenal incidentaloma was found on CT or MRI. CS was ruled out by the criteria detailed above. In all patients, primary aldosteronism was excluded by a serum aldosterone:renin ratio $<30$ and pheochromocytomas if at least two collections for urinary metanephrines and normetanephrines were normal.

- There were 73 subjects affected by common medical conditions suggestive of hypercortisolism (as summarized by Nieman et al. (3)), age $40 \pm 15$ years, BMI $33 \pm 8 \mathrm{~kg} / \mathrm{m}^{2}$. Among them, 54 were obese, $12 \mathrm{had}$ severe depression, 30 had metabolic syndrome, and 36 had polycystic ovary syndrome. All patients had suppressed cortisol levels of below $50 \mathrm{nmol} / \mathrm{l}$ after the $1 \mathrm{mg}$ DST and had two normal UFC consecutive collections. This non-CS group underwent clinical and biochemical follow-up for at least 12 months.

- Of the 75 patients newly diagnosed with adrenal insufficiency (age $51 \pm 17$ years, BMI $26 \pm 4 \mathrm{~kg} / \mathrm{m}^{2}$ ), 28 had the primary form (all with autoimmune adrenalitis; we excluded patients with bilateral adrenalectomy) and 47 had the secondary form (all with hypopituitarism due to neurosurgery in 27 subjects and to surgery along with radiotherapy for pituitary adenoma or craniopharyngioma in 16 patients, to pituitary apoplexy in three cases, and to traumatic brain injury and pituitary stalk interruption in one patient). Clinical diagnosis was biochemically confirmed by basal serum morning cortisol levels below $138 \mathrm{nmol} / \mathrm{l}$ in primary adrenal insufficiency and by basal cortisol levels below $138 \mathrm{nmol} / \mathrm{l}$ or cortisol response to standard- or low-dose ACTH testing below $440 \mathrm{nmol} / \mathrm{l}$ in secondary adrenal insufficiency (18). None were undergoing glucocorticoid replacement therapy or taking exogenous glucocorticoids during the study.

- The 104 healthy subjects were age matched with those in the non-CS group (age $38 \pm 17$ years, mean BMI $23 \pm 5 \mathrm{~kg} / \mathrm{m}^{2}$ ). These subjects showed no signs and symptoms of hypercortisolism and no history of severe and/or chronic illness (particularly of endocrine origin). None were taking exogenous glucocorticoids or drugs that could interfere with the HPA axis. All studies were performed in accordance with the guidelines proposed in the Declaration of Helsinki; the local ethics committee approved the protocol and all subjects gave informed consent.

\section{Salivary sample collection and analyses}

In healthy subjects and patients, morning salivary cortisol (MSC) was collected upon waking up and LNSC before going to sleep (between 1100 and $1200 \mathrm{~h}$, not performed in patients with adrenal insufficiency). Patients and volunteers were advised to soak the absorbent cotton of Salivette device (Sarstedt, Numbrecht, Germany) in the saliva for 2 or $3 \mathrm{~min}$; samples were then stored at $+4{ }^{\circ} \mathrm{C}$. To avoid any source of food, blood, smoke, or licorice contamination, samples were collected at least $30 \mathrm{~min}$ before or $2 \mathrm{~h}$ after taking a meal or a drink and all participants brushed their teeth after saliva collection and avoided smoking or eating licorice. After centrifugation, we obtained at least $1 \mathrm{ml}$ saliva in all collections (repeating the procedures in a few days if the patient did not provide an adequate volume), and then samples were stored at $-20{ }^{\circ} \mathrm{C}$ until assay with a commercially available RIA kit (Radim, Rome, Italy) with an assay sensitivity of $0.5 \mathrm{ng} / \mathrm{ml}$, an intra-assay variation of $3 \%$, and an inter-assay 
Table 1 Morning salivary cortisol (MSC) and late-night salivary cortisol (LNSC) levels.

\begin{tabular}{|c|c|c|c|}
\hline Population $(n)$ & Male/female & MSC (ng/ml) & LNSC (ng/ml) \\
\hline Healthy subjects (104) & $42 / 62$ & $7.87 \pm 3.58$ & $1.81 \pm 1.41$ \\
\hline CS (82) & $22 / 60$ & $24.47 \pm 40.54^{\star, \neq, a, b, c}$ & $31.94 \pm 71.67^{\star, \ddagger, a, b, c}$ \\
\hline CD (52) & $12 / 40$ & $16.23 \pm 14.72^{\star, a, c}$ & $13.95 \pm 8.83^{\star, a, c}$ \\
\hline Newly diagnosed CD (41) & $10 / 31$ & $17.46 \pm 15.84^{\S, \uparrow}$ & $15.15 \pm 9.24^{\S, \pi}$ \\
\hline Recurrence of CD (11) & $2 / 9$ & $10.11 \pm 2.43$ & $9.45 \pm 5.27^{\mathrm{c}}$ \\
\hline$C D$ in remission (27) & $6 / 21$ & $6.59 \pm 4.36^{\dagger}$ & $1.48 \pm 0.85^{\dagger}$ \\
\hline Ectopic CS (13) & $5 / 8$ & $71.28 \pm 83.89^{*, t, \ddagger}$ & $126.33 \pm 150.16^{*, t, \pm}$ \\
\hline Adrenal CS (17) & $5 / 12$ & $12.56 \pm 8.01^{*}$ & $14.78 \pm 15.59^{*}$ \\
\hline Non-CS (73) & $19 / 54$ & $10.43 \pm 5.56^{*, \|}$ & $2.25 \pm 1.65^{\|}$ \\
\hline Adrenal incidentaloma (45) & $16 / 29$ & $10.12 \pm 5.12^{*}$ & $2.57 \pm 1.46^{\star}$ \\
\hline Adrenal insufficiency (75) & $37 / 38$ & $1.27 \pm 1.23^{*}$ & NC \\
\hline Primary adrenal insufficiency (28) & $11 / 17$ & $1.40 \pm 0.94$ & NC \\
\hline Secondary adrenal insufficiency (47) & $26 / 21$ & $1.25 \pm 1.27$ & NC \\
\hline
\end{tabular}

$\mathrm{CD}$, Cushing's disease; $\mathrm{CS}$, Cushing's syndrome (CD+ectopic $\mathrm{CS}+$ adrenal $\mathrm{CS})$; NC, non-collected; ${ }^{*} P<0.001$ vs healthy subjects; ${ }^{\dagger} P<0.01$ vs $C D ;{ }^{\ddagger} P<0.01$ vs adrenal $C S,{ }^{\S} P<0.001$ vs recurrence of $C D ; " ~ P<0.01$ vs $C D$ in remission; ${ }^{\pi} P<0.05$ vs newly diagnosed $C D$;

${ }^{\mathrm{a}} P<0.01$ vs non-CS; ${ }^{\mathrm{b}} P<0.001$ vs adrenal incidentaloma; ${ }^{\mathrm{c}} P<0.001$ vs healthy subjects + non-CS.

variation of $9 \%$. This cortisol assay does not show significant cross-reaction with cortisone, desoxycorticosterone, corticosterone, estradiol, testosterone, and 17-hydroxyprogesterone; coefficients of variation were $7 \%$ in the high range and $4 \%$ in the low range.

\section{Statistical analysis}

Continuous data are shown as mean and S.D. We first assessed the normality of distribution using the Kolmogorov-Smirnov $\mathrm{Z}$ test and then compared the means by Student's $t$-test for unpaired data with the correct $P$ value adjusted after the Levene's test for equality of variances. We performed receiver operating curve (ROC) analyses to study the sensitivity and specificity of each threshold value. Database management and statistical analysis were performed using the SPSS 17 software package (SPSS, Inc.). Significance level was set at $P$ value $<5 \%$ for all tests.

\section{Results}

Concentrations of MSC and LNSC and $P$ values are summarized in Table 1, and results of ROC analyses are summarized in Table 2 (to convert salivary cortisol levels from nanograms per milliliter to nanomole per liter multiply by 2.76). Considering hypercortisolism, all cutoff values for MSC had low sensitivity and specificity, so we took into account only LNSC values (depicted in Fig. 1). In contrast, for adrenal insufficiency, we took into account only MSC values.

\section{Cushing's syndrome}

LNSC levels were higher in CS patients (31.94 $\pm 71.67 \mathrm{ng} / \mathrm{ml})$ than in healthy subjects $(1.81$ $\pm 1.41 \mathrm{ng} / \mathrm{ml})$ and non-CS patients $(2.57 \pm 1.46 \mathrm{ng} / \mathrm{ml})$. A threshold value of $5.24 \mathrm{ng} / \mathrm{ml}$ provided high sensitivity and specificity; the same value distinguished CS subjects from all controls and CD patients from healthy subjects. With the proposed cutoff value, we detected 79 of 82 CS patients (51/52 CD, 15/17 adrenal CS, and 17/17 ectopic CS) and ruled out CS in the majority of non-CS patients (69 of 73). We found higher LNSC levels in patients with ectopic CS than in those with $\mathrm{CD}$ and adrenal CS $(126.33 \pm 150.16$ vs $13.95 \pm 8.83$ vs 14.78 $\pm 15.59 \mathrm{ng} / \mathrm{ml}$ respectively).

\section{Non-CS and adrenal incidentaloma}

In the non-CS group, LNSC levels were similar to those in healthy subjects, whereas LNSC levels were higher in patients with adrenal incidentaloma than in healthy controls $(2.57 \pm 1.46$ vs $1.81 \pm 1.41 \mathrm{ng} / \mathrm{ml})$, with no threshold value in terms of sensitivity or specificity. Patients with CS had higher levels of LNSC than non-CS and adrenal incidentaloma subjects $(31.94 \pm 71.67$ vs $2.25 \pm 1.65$ and $2.57 \pm 1.46 \mathrm{ng} / \mathrm{ml}$ respectively). We found no difference in MSC and LNSC levels between the non-CS and adrenal incidentaloma groups.

\section{Recurrence and remission of CD}

LNSC levels were higher in patients newly diagnosed with $\mathrm{CD}$ or recurrence of $\mathrm{CD}$ than in those with $\mathrm{CD}$ in

Table 2 Cutoff values for late-night salivary cortisol (LNSC).

\begin{tabular}{lcccc}
\hline Population & $\begin{array}{c}\text { LNSC } \\
(\mathrm{ng} / \mathrm{ml})\end{array}$ & $\begin{array}{c}\text { Sensi- } \\
\text { tivity (\%) }\end{array}$ & $\begin{array}{c}\text { Speci- } \\
\text { ficity (\%) }\end{array}$ & AUC \\
\hline CS vs healthy subjects & 5.24 & 96.3 & 97.1 & 0.992 \\
CD vs healthy subjects & 5.24 & 98.1 & 97.1 & 0.991 \\
CS vs non-CS & 5.15 & 96.3 & 94.5 & 0.986 \\
CD vs non-CS & 5.15 & 98.1 & 96.5 & 0.984 \\
CD recurrence & 5.15 & 100 & 95.5 & 0.987 \\
$\quad$ vs non-CS & & & & \\
$\begin{array}{l}\text { CS vs adrenal } \\
\quad \text { incidentaloma }\end{array}$ & 4.95 & 97.6 & 97.8 & 0.985 \\
\end{tabular}

$\mathrm{CD}$, Cushing's disease; $C S$, Cushing's syndrome (CD + ectopic CS + adrenal CS). 


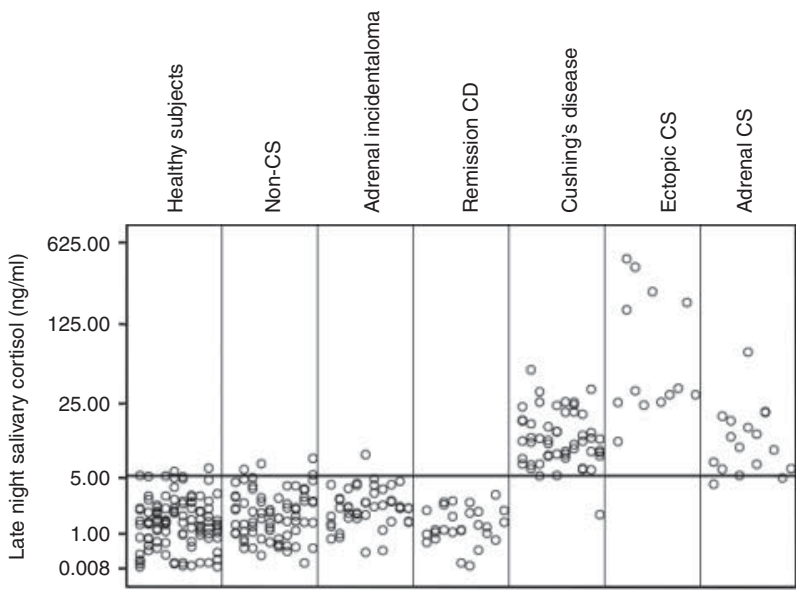

Figure 1 Plot of late-night salivary cortisol values: black line cross indicates cutoff value of $5.24 \mathrm{ng} / \mathrm{ml}$. Salivary cortisol concentration is depicted as a logarithmic base 5 scale.

remission $(15.15 \pm 9.24$ and $9.45 \pm 5.27$ vs 1.48 $\pm 0.85 \mathrm{ng} / \mathrm{ml}$ respectively), with no difference in LNSC levels between patients with $\mathrm{CD}$ in remission and healthy subjects, and higher LNSC levels in non-CS patients than in those with $\mathrm{CD}$ in remission $(2.25$ $\pm 1.65 \mathrm{vs} 1.48 \pm 0.85 \mathrm{ng} / \mathrm{ml})$. We found higher LNSC levels in newly diagnosed CD patients than in those with recurrence of CD $(15.15 \pm 9.24 \mathrm{vs} 9.45 \pm 5.27 \mathrm{ng} / \mathrm{ml})$. In the latter group, LNSC levels were higher than those in patients with non-CS, with a reliable threshold value.

\section{Adrenal insufficiency}

MSC levels were higher in healthy subjects than in patients with adrenal insufficiency $(7.87 \pm 3.58$ vs $1.27 \pm 1.23 \mathrm{ng} / \mathrm{ml}$ ); a value of $2.65 \mathrm{ng} / \mathrm{ml}$ reliably distinguished patients with adrenal insufficiency from healthy subjects (70 of 75 patients, $97.1 \%$ sensitivity and $93.3 \%$ specificity, AUC 0.970). No difference for MSC levels was found between primary and secondary adrenal insufficiency.

\section{Discussion}

Despite improvement in laboratory and imaging techniques, diagnosis of CS remains a challenge, particularly if is to be made before patients developed the full-blown clinical disease. In light of this, physicians may be called to exclude the different forms of CS from the most common ones in the general population: obesity, depression, hirsutism, and metabolic syndrome (3). UFC collection and the $1 \mathrm{mg}$ DST are simple, but neither is able to make a certain diagnosis of CS $(15,20$, $21)$. The LNSC test, as proposed recently $(5,6,7,10$, $11,12,14)$, is a reliable, noninvasive, stress-free, and low-cost procedure to diagnose CS. Moreover, elevation of LNSC levels might be the first abnormality to be checked in the follow-up after surgery (22).
As reported in some studies $(2,5,6,7,10,11,12$, 14), we found that LNSC levels were higher in CS; a threshold value above $5.24 \mathrm{ng} / \mathrm{ml}$ provided a good accuracy to detect endogenous hypercortisolism, and in particular to discover CD, the most common form. LNSC was able to differentiate CS patients from the control population, which included not only healthy subjects but also patients with suspected CS, and our proposed threshold value is consistent with other data reported in the literature and obtained with RIAs $(5,11,23)$.

Recently, Raff (1) has proposed a flow chart for CS diagnosis that envisages the LNSC test as the initial screening procedure, and in case of ambiguity or contradictory results, he has suggested other tests to confirm CS diagnosis. Our data are in agreement with this diagnostic plan: normal LNSC levels may rule out CS, unless there is a very high index of suspicion, particularly if a cyclic form of CS is suspected. We have undertaken a clinical and biochemical follow-up for at least 1 year to exclude any non-CS patients developing into overt CS patients, and we found none. When we retested the four cases in the non-CS group that showed slightly elevated initial levels of LNSC, we did not find the previous increase: probably the first elevated LNSC value was due to blood contamination of the salivary sample or to stress/physical exercise before their saliva sampling.

One patient with CD and two patients with adrenal CS had normal LNSC levels, but the persistent elevation of UFC levels and the lack of cortisol suppression detected by the $1 \mathrm{mg}$ DST led to a correct diagnosis. Lower levels of LNSC may be due to inadequate soaking of the saliva collection device or to some fluctuation as in the case of cyclical CS. The rapid onset and progression of severe hypercorticism suggest ectopic CS, which may be difficult to pinpoint, given its being occult in up to $20 \%$ of the cases $(13,24)$. LNSC levels were higher in ectopic CS than in pituitary or adrenal CS, probably because higher cortisol secretion is observed in the ectopic form. We suggest that only very high levels of LNSC could induce one to suspect ectopic CS, because there is some overlap with CD when LNSC values are three to six times the proposed cutoff value of $5.24 \mathrm{ng} / \mathrm{ml}$.

Another challenge for endocrinologists is the definition of patients that may relapse with $\mathrm{CD}$ after successful neurosurgery. There are data about the efficacy in relapse prediction of stimulatory tests $(22$, $25,26)$ and fewer about salivary cortisol (27). We demonstrated higher LNSC levels in active CD patients than in those with $\mathrm{CD}$ in remission and also in those with non-CS than in those with CD in remission, confirming the data published by Carrasco et al. (27) and suggesting salivary cortisol as a simple and reliable tool to follow up patients with $\mathrm{CD}$ in remission. In clinical practice, some features of hypercorticism (e.g. overweight, hypertension, depression, or impaired fasting glucose) in patients with CD in remission may 
only partially ameliorate, so an altered circadian cortisol rhythm may be a marker of relapse. We suggest to use the LNSC test in the follow up of CD patients after surgery, especially in patients with residual signs or symptoms that may overlap with CS features. We found higher LNSC levels in patients with newly diagnosed CD than in those with recurrence. We do not know why relapse appears with lower LNSC levels; it is probably because after neurosurgery, the patients are stringently followed up and thus diagnosis of recurrence is a prompter.

In patients with adrenal incidentaloma, LNSC levels were higher than those in healthy subjects and were effective to rule out CS: only one of 42 patients with adrenal incidentaloma showed a LNSC value higher than the proposed cutoff value, and on repeating the LNSC test a few months later, we found a normal value. Although in our series a normal LNSC value in adrenal incidentaloma can rule out CS with certainty, we did not evaluate SH due to the selection criteria of our group, so we do not suggest using the LNSC test, rather than the $1 \mathrm{mg}$ DST, as a suitable screening procedure for $\mathrm{SH}$, as first reported by Masserini et al. (28).

Diagnosis of adrenal insufficiency is a matter of clinical debate, although a recent meta-analysis has suggested using serum cortisol after ACTH injection (18), but apart from dynamic testing, the use of salivary cortisol is less established in adrenal insufficiency, because both Deutschbein et al. (2) and Restituto et al. (6) have reposed a low accuracy for diagnosis. In our series, we confirmed our previous results that MSC levels are lower in patients with established adrenal insufficiency than in healthy controls (19). We still use dynamic tests to discover adrenal insufficiency, but we suggest using periodic salivary cortisol evaluation to follow up patients (especially with pituitary disease) in order to perform the dynamic test at the correct time.

Our study has several limitations. It is noteworthy that methodologies of salivary cortisol analyses are critical due to assay differences and control populations considered, so we suggest that every endocrinologist use cutoff values of known sensitivity and specificity based on the local measurements at various times of the day and based on a control population with obesity, diabetes, or depression, as has been suggested recently (24).

Our experience is in agreement with the concept of the accuracy and feasibility of LNSC as a first step in the diagnostic work-up of the HPA axis disorder (both CS and adrenal insufficiency). We suggest that periodic LNSC measurement may represent a simple and effective way to follow up CD patients in remission and for early identification of patients that relapse.

\section{Declaration of interest}

The authors declare that there is no conflict of interest that could be perceived as prejudicing the impartiality of the research reported.

\section{Funding}

This research did not receive any specific grant from any funding agency in the public, commercial or not-for-profit sector.

\section{References}

1 Raff H. Cushing's syndrome: diagnosis and surveillance using salivary cortisol. Pituitary $2012 \quad 15$ 64-70. (doi:10.1007/ s11102-011-0333-0)

2 Deutschbein T, Broecker-Preuss M, Flitsch J, Jaeger A, Althoff R, Walz MK, Mann K \& Petersenn S. Salivary cortisol as a diagnostic tool for Cushing's syndrome and adrenal insufficiency: improved screening by an automatic immunoassay. European Journal of Endocrinology 2012166 613-618. (doi:10.1530/EJE-11-0945)

3 Nieman LK, Biller BM, Findling JW, Newell-Price J, Savage MO, Stewart PM \& Montori VM. The diagnosis of Cushing's syndrome: an Endocrine Society Clinical Practice Guideline. Journal of Clinical Endocrinology and Metabolism 200893 1526-1540. (doi:10.1210/jc.2008-0125)

4 Pecori Giraldi F, Ambrogio AG, De Martin M, Fatti LM, Scacchi M \& Cavagnini F. Specificity of first-line tests for the diagnosis of Cushing's syndrome: assessment in a large series. Journal of Clinical Endocrinology and Metabolism 200792 4123-4219. (doi:10.1210/jc.2007-0596)

5 Papanicolaou DA, Mullen N, Kyrou I \& Nieman LK. Nighttime salivary cortisol: a useful test for the diagnosis of Cushing's syndrome. Journal of Clinical Endocrinology and Metabolism 2002 87 4515-4521. (doi:10.1210/jc.2002-020534)

6 Restituto P, Galofré JC, Gil MJ, Mugueta C, Santos S, Monreal JI \& Varo N. Advantage of salivary cortisol measurements in the diagnosis of glucocorticoid related disorders. Clinical Biochemistry 200841 688-692. (doi:10.1016/j.clinbiochem.2008.01.015)

7 Vilar L, Freitas MC, Naves LA, Canadas V, Albuquerque JL, Botelho CA, Egito CS, Arruda MJ, Silva LM, Arahata CM et al. The role of non-invasive dynamic tests in the diagnosis of Cushing's syndrome. Journal of Endocrinological Investigation 200831 10081013.

8 Elamin MB, Murad MH, Mullan R, Erickson D, Harris K, Nadeem S, Ennis R, Erwin PJ \& Montori VM. Accuracy of diagnostic tests for Cushing's syndrome: a systematic review and metaanalyses. Journal of Clinical Endocrinology and Metabolism 200893 1553-1562. (doi:10.1210/jc.2008-0139)

9 Carroll T, Raff H \& Findling JW. Late-night salivary cortisol for the diagnosis of Cushing syndrome: a meta-analysis. Endocrine Practice 200915 335-342. (doi:10.4158/EP09023OR)

10 Cardoso EM, Arregger AL, Tumilasci OR \& Contreras LN. Diagnostic value of salivary cortisol in Cushing's syndrome. Clinical Endocrinology 200970 516-521. (doi:10.1111/j.13652265.2008.03381.x)

11 Nunes ML, Vattaut S, Corcuff JB, Rault A, Loiseau H, Gatta B, Valli N, Letenneur L \& Tabarin A. Late-night salivary cortisol for diagnosis of overt and subclinical Cushing's syndrome in hospitalized and ambulatory patients. Journal of Clinical Endocrinology and Metabolism 200994 456-462. (doi:10.1210/jc. 2008-1542)

12 Sereg M, Toke J, Patócs A, Varga I, Igaz P, Szücs N, Horányi J, Pusztai P, Czirják S, Gláz E et al. Diagnostic performance of salivary cortisol and serum osteocalcin measurements in patients with overt and subclinical Cushing's syndrome. Steroids 2011 76 38-42. (doi:10.1016/j.steroids.2010.08.007)

13 Alexandraki KI \& Grossman AB. The ectopic ACTH syndrome. Reviews in Endocrine and Metabolic Disorders 201011 117-126. (doi:10.1007/s11154-010-9139-z)

14 Erickson D, Singh RJ, Sathananthan A, Vella A \& Bryant SC. Latenight salivary cortisol for diagnosis of Cushing's syndrome by liquid chromatography/tandem mass spectrometry assay. Clinical Endocrinology $2012 \mathbf{7 6}$ 467-472. (doi:10.1111/j.1365-2265. 2011.04239.x) 
15 Boscaro M \& Arnaldi G. Approach to the patient with possible Cushing's syndrome. Journal of Clinical Endocrinology and Metabolism 200994 3121-3131. (doi:10.1210/jc.2009-0612)

16 Terzolo M, Bovio S, Reimondo G, Pia A, Osella G, Borretta G \& Angeli A. Subclinical Cushing's syndrome in adrenal incidentalomas. Endocrinology and Metabolism Clinics of North America 2005 34 423-439. (doi:10.1016/j.ecl.2005.01.008)

17 Chiodini I. Clinical review: diagnosis and treatment of subclinical hypercortisolism. Journal of Clinical Endocrinology and Metabolism 201196 1223-1236. (doi:10.1210/jc.2010-2722)

18 Kazlauskaite R, Evans AT, Villabona CV, Abdu TA, Ambrosi B, Atkinson AB, Choi CH, Clayton RN, Courtney CH, Gonc EN et al. Corticotropin tests for hypothalamic-pituitary-adrenal insufficiency: a metaanalysis. Journal of Clinical Endocrinology and Metabolism 200893 4245-4253. (doi:10.1210/jc.2008-0710)

19 Ceccato F, Albiger N, Reimondo G, Frigo A, Ferasin S, Occhi G, Mantero F, Terzolo M \& Scaroni C. Assessment of glucocorticoid therapy with salivary cortisol in secondary adrenal insufficiency. European Journal of Endocrinology 2012167 769-776. (doi:10. 1530/EJE-12-0534)

20 Vilar L, Freitas Mda C, Faria M, Montenegro R, Casulari LA, Naves L \& Bruno OD. Pitfalls in the diagnosis of Cushing's syndrome. Arquivos Brasileiros de Endocrinologia e Metabologia 200751 1207-1216. (doi:10.1590/S0004-2730200700080 0006)

21 Alexandraki KI \& Grossman AB. Is urinary free cortisol of value in the diagnosis of Cushing's syndrome? Current Opinion in Endocrinology, Diabetes and Obesity $2011 \quad 18$ 259-263. (doi:10.1097/MED.0b013e3283487193)

22 Bou Khalil R, Baudry C, Guignat L, Carrasco C, Guibourdenche J, Gaillard S, Bertagna X \& Bertherat J. Sequential hormonal changes in 21 patients with recurrent Cushing's disease after successful pituitary surgery. European Journal of Endocrinology 2011165 729-737. (doi:10.1530/EJE-11-0424)
23 Inder WJ, Dimeski G \& Russell A. Measurement of salivary cortisol in - laboratory techniques and clinical indications. Clinical Endocrinology 201277 645-651. (doi:10.1111/j.1365-2265. 2012.04508.x)

24 Isidori AM \& Lenzi A. Ectopic ACTH syndrome. Arquivos Brasileiros de Endocrinologia e Metabologia 200751 1217-1225. (doi:10.1590/S0004-27302007000800007)

25 Losa M, Bianchi R, Barzaghi R, Giovanelli M \& Mortini P. Persistent adrenocorticotropin response to desmopressin in the early postoperative period predicts recurrence of Cushing's disease. Journal of Clinical Endocrinology and Metabolism 200994 3322-3328. (doi:10.1210/jc.2009-0844)

26 Barbot M, Albiger N, Koutroumpi S, Ceccato F, Frigo AC, Manara R, Fassina A, Gardiman MP, Scanarini M, Mantero F et al. Predicting late recurrence in surgically-treated patients with Cushing's disease. Clinical Endocrinology 2013 In press. (doi:10.1111/cen.12133)

27 Carrasco CA, Coste J, Guignat L, Groussin L, Dugué MA, Gaillard S, Bertagna X \& Bertherat J. Midnight salivary cortisol determination for assessing the outcome of transsphenoidal surgery in Cushing's disease. Journal of Clinical Endocrinology and Metabolism 200893 4728-4734. (doi:10.1210/jc.2008-1171)

28 Masserini B, Morelli V, Bergamaschi S, Ermetici F, EllerVainicher C, Barbieri AM, Maffini MA, Scillitani A, Ambrosi B, Beck-Peccoz P et al. The limited role of midnight salivary cortisol levels in the diagnosis of subclinical hypercortisolism in patients with adrenal incidentaloma. European Journal of Endocrinology 2009160 87-92. (doi:10.1530/EJE-08-0485)

Received 25 February 2013

Revised version received 16 April 2013

Accepted 22 April 2013 